\title{
First two cases of craniomaxillofacial fibrous dysplasia from Nepal - case series
}

This article was published in the following Dove Press journal: Clinical, Cosmetic and Investigational Dentistry

\author{
Neha Mishra' \\ Sourav Kumar Rout ${ }^{2}$ \\ 'Department of Oral and Maxillofacial \\ Pathology and Microbiology, Chitwan \\ Medical College and Teaching Hospital, \\ Bharatpur-10, Chitwan, Nepal; \\ ${ }^{2}$ Department of Oral and Maxillofacial \\ Surgery, Chitwan Medical College \\ and Teaching Hospital, Bharatpur-10, \\ Chitwan, Nepal
}

\begin{abstract}
Fibrous dysplasia is a benign fibro-osseous disease of the bone, which is most commonly associated with congenital mutations in cAMP regulating protein Gs $\alpha$ coded by GNAS-1 gene. Often it is seen involving the craniofacial skeleton and can range from an asymptomatic monostotic form to polyostotic variant involving almost all the bones of the skull, thereby leading to functional and esthetic problems. This requires a continuous monitoring of the involved region throughout the life of the patient, even after the surgical interventions. We are presenting two cases of craniofacial form of fibrous dysplasia. One case shows monostotic form, while the other case shows features of polyostotic form of disease. To the best of our knowledge, these are the first two cases of craniomaxillofacial fibrous dysplasia from Nepal, which will be reported and published.
\end{abstract}

Keywords: monostotic, polyostotic, Jaffe-Lichtenstein syndrome, McCune-Albright syndrome, fibro-osseous

\section{Introduction}

Fibrous dysplasia is a benign bone lesion, which is named so because of its characteristic property of replacement of normal bone by fibrous tissue. ${ }^{1}$ It is a sporadic skeletal disorder caused by mutations of gene encoding for alpha subunit of G-protein. ${ }^{2}$ This mutation results in proliferation and differentiation of preosteoblasts that eventually affects the bone, replacing its marrow by fibrous tissue and randomly arranged woven bone. ${ }^{3}$ The consequences can range from asymptomatic defects to severe bone deformities and increased fragility involving either one bone (monostotic) or multiple bones (polyostotic). Monostotic form is more common compared to polyostotic form. ${ }^{4,5}$ Polyostotic form of fibrous dysplasia can exist clinically in different forms depending on its co-existences with skin pigmentation and endocrinopathies. A third form known as craniofacial fibrous dysplasia is considered a separate entity by some authors; however, others believe it to be a form of polyostotic form of fibrous dysplasia involving multiple cranial bones. ${ }^{3}$ Here, we are presenting two cases of craniomaxillofacial form of fibrous dysplasia, which are most likely the first two cases to be reported and published from Nepal.

\section{Case report}

We are describing here two cases of craniomaxillofacial form of fibrous dysplasia. The first case was seen in a 34-year-old female patient, resident of Nepal. No family history of bone metabolic disorders was reported. She came with the complaint of swelling 
of gums in the upper right back region of the jaw since last 9 months. Swelling was occasionally associated with pain, but there was no history of pus discharge or bleeding. The patient gave a history of eventful extraction of teeth 4 months from the same area.

On clinical examination, a bony hard, non-tender swelling was seen over the maxillary tuberosity measuring approximately $0.5 \times 1 \mathrm{~cm}$ and extending from the right maxillary first premolar involving the area of third molar region, maxillary tuberosity, and part of palate (Figure 1).

On occlusal radiograph, the expansion of cortical plates was evident with ground glass appearance (Figure 2).

The skin and mucosa did not show any signs of pigmentation, and no endocrinopathies were detected.

The second case presented was seen in a 25 -year-old male patient who reported with a complaint of growth in his left supraorbital and frontal bone regions. The growth was slow and persisted since last 9 years. There was no history of pain. There was no complaint of optic and auditory function impairment. Our institution's medicine department was consulted to check if any associated endocrine disorder is present. His thyroid function tests and testosterone, prolactin, insulin-like growth factor, and follicle-stimulating hormone (FSH)/luteinizing hormone (LH) levels showed no signs of endocrinopathy. No associated skin pigmentations were detected (Figure 3). Three years ago, the patient underwent a radiographic imaging (Figure 4) and computed tomography scans on which a diffuse thickening of cranial bones (frontal, occipital, sphenoid, zygomatic, petrous, and mastoid bones of both sides and temporal and parietal bones of the left side) involving mainly outer table is noted (Figure 5).

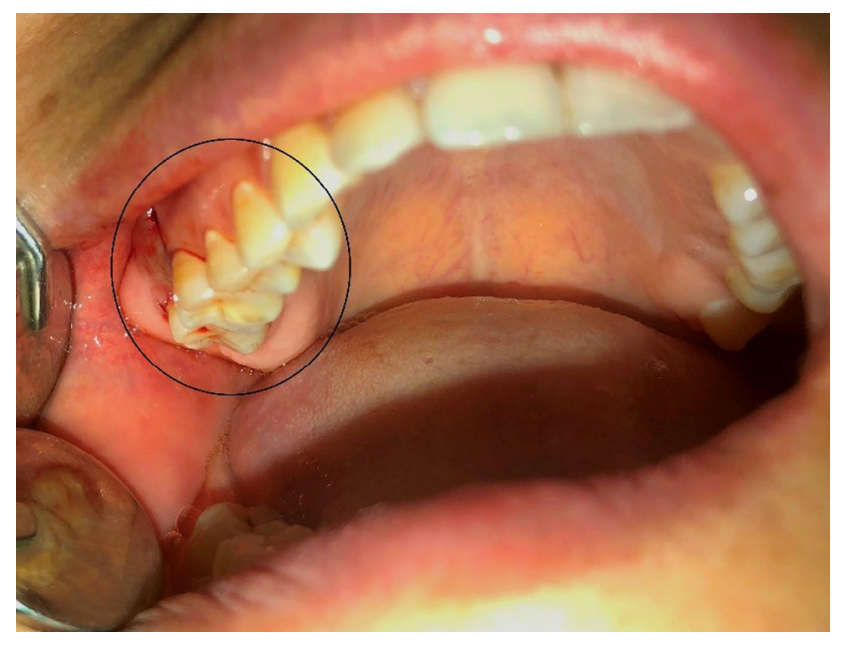

Figure I Bony swelling present over the posterior part of maxilla involving the maxillary tuberosity and part of palate.
In both the cases, incisional biopsies followed by surgical corrections were performed (Figure 6). The lesions on histopathological examination revealed "C"-shaped curvilinear trabeculae of the woven bone and stroma with fibroblastic proliferation. No hematopoietic and adipose tissues were found to be present in the marrow cavity. The trabeculae showed the presence of osteocytes and the absence of peripheral rimming of osteoblasts suggestive of fibrous dysplasia (Figures 7 and 8).

\section{Discussion}

Fibrous dysplasia as defined by Eversole is "a benign, nonneoplastic intramedullary cellular proliferation of fibroblasts, with formation of irregular trabeculae of bone or ovoid calcifications that show indistinct, non encapsulated borders."

It is broadly classified into two forms, monostotic and polyostotic, depending on the number of bones involved. The polyostotic form can further be found associated either as a part of Jaffe-Lichtenstein syndrome or as a part of McCune-Albright syndrome. ${ }^{7}$ The monostotic form has been reported to occur more frequently and represents approximately $75 \%$ of fibrous dysplasia cases. The craniofacial bone is the most common site and least common includes tibia and humerus. In most cases, it presents with pain and pathologic fracture. However, the degree of bone deformity is less severe when compared to that of polyostotic fibrous dysplasia. ${ }^{8}$

Approximately only $20 \%-30 \%$ of fibrous dysplasia are polyostotic. The most common sites of involvement include the skull and facial bones. The dysplasia can be present unilaterally or bilaterally. Although the polyostotic form is

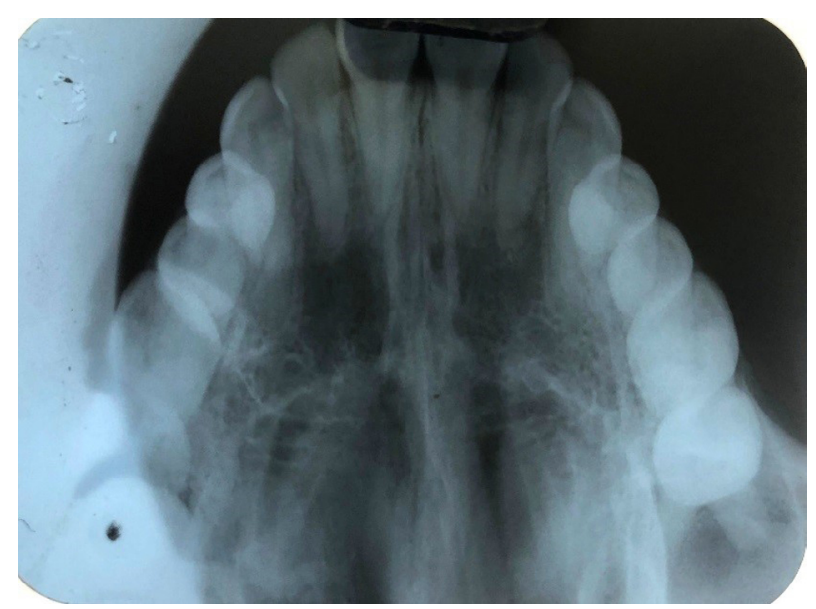

Figure 2 Occlusal radiograph showing fibrous dysplasia with ground glass appearance over the right side extending from first premolar to the area beyond maxillary tuberosity. 


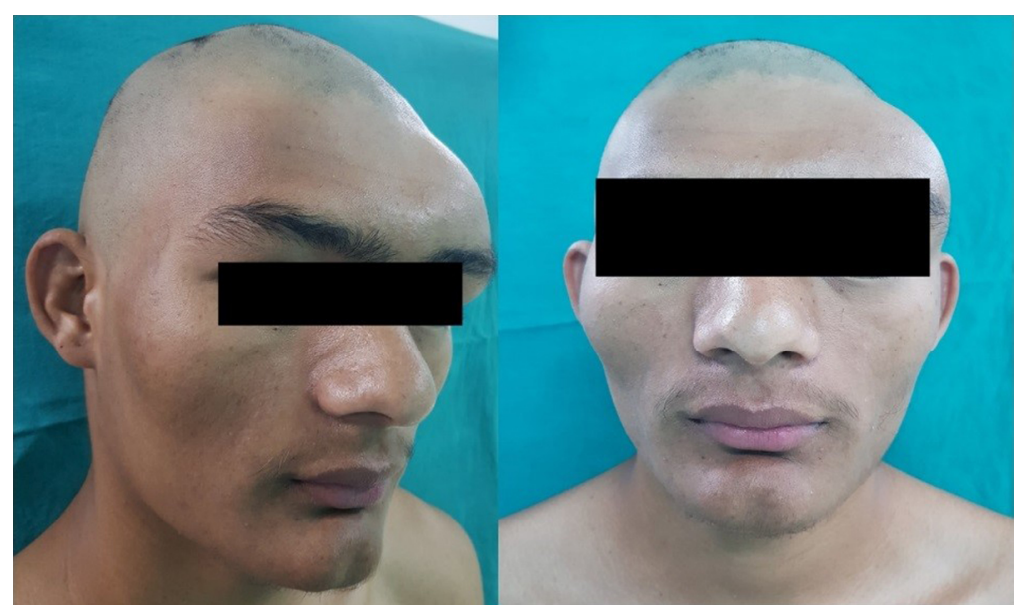

Figure 3 Preoperative images showing facial asymmetry due to bony hard expansion of craniofacial bones.

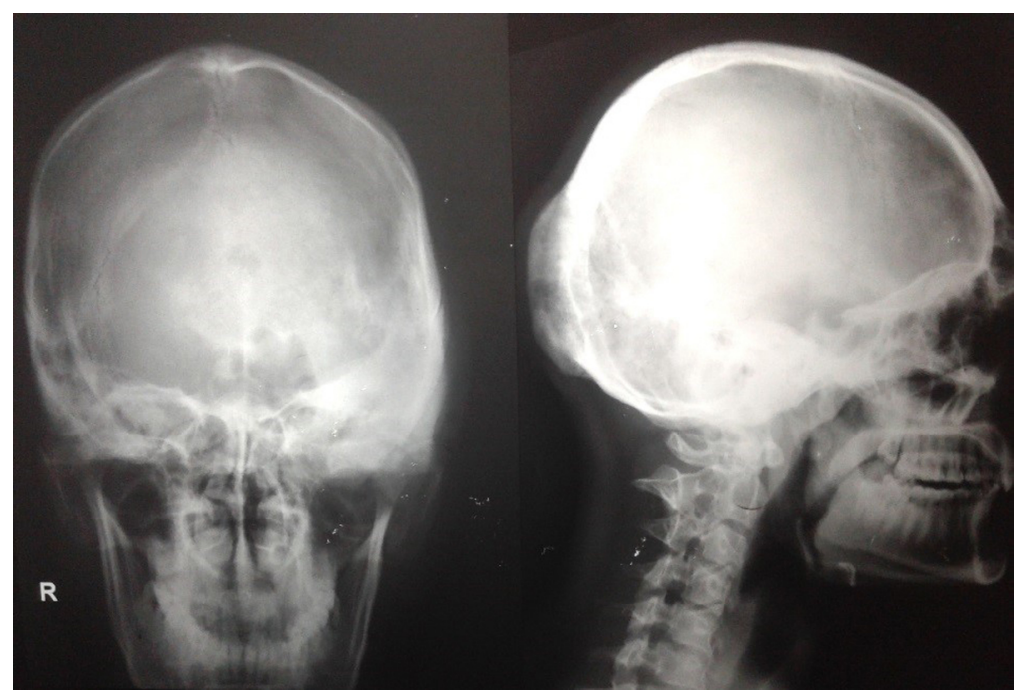

Figure 4 Lateral and PA views of radiographs showing ground glass appearance involving multiple cranial bones. Abbreviation: PA, posteroanterior.

A

B

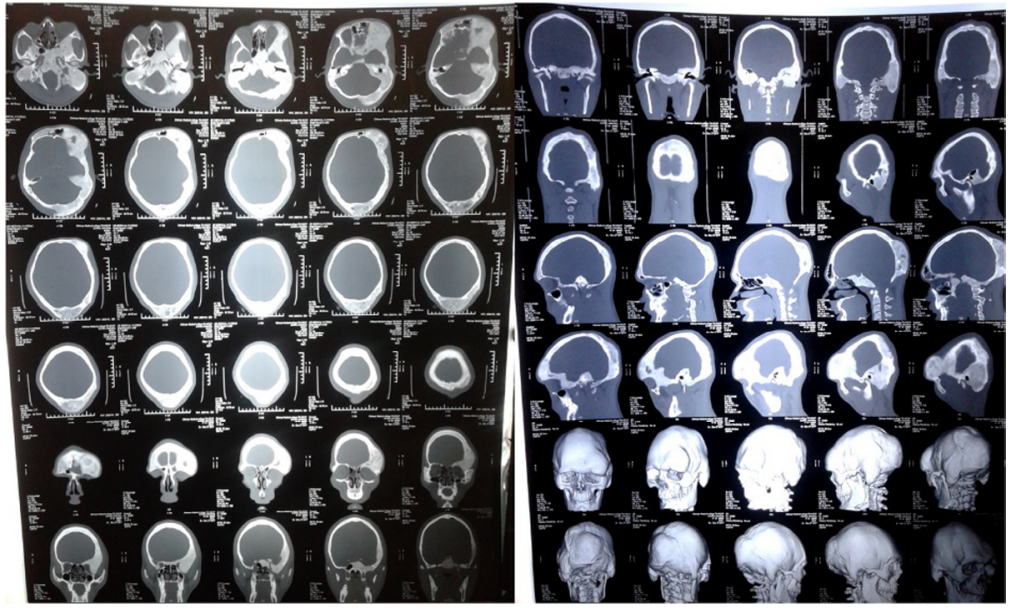

Figure 5 (A) CT and (B) 3D CT scans showing expansile growth of the multiple skull and facial bones. Abbreviation: $\mathrm{CT}$, computed tomography. 


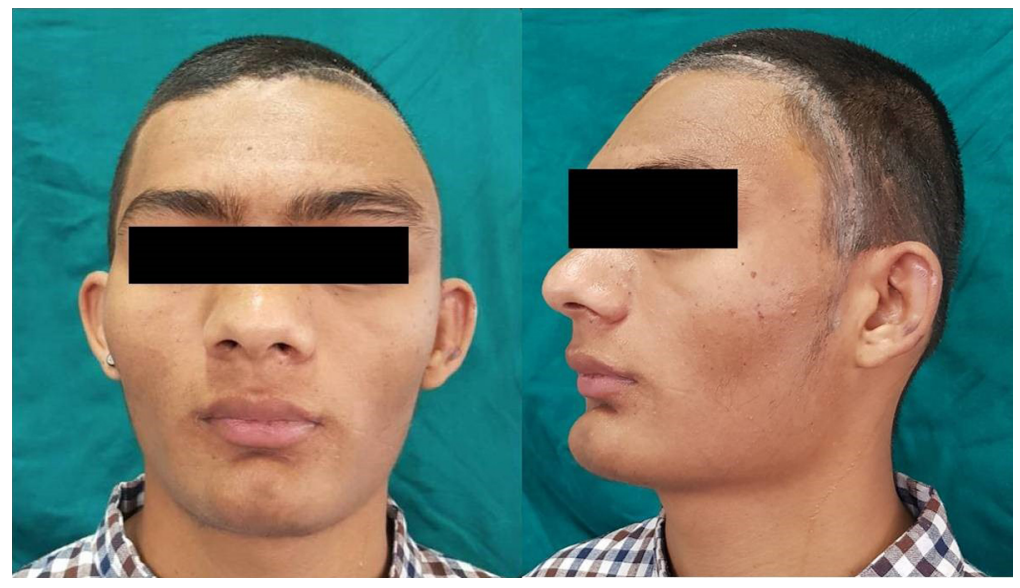

Figure 6 Postoperative images.

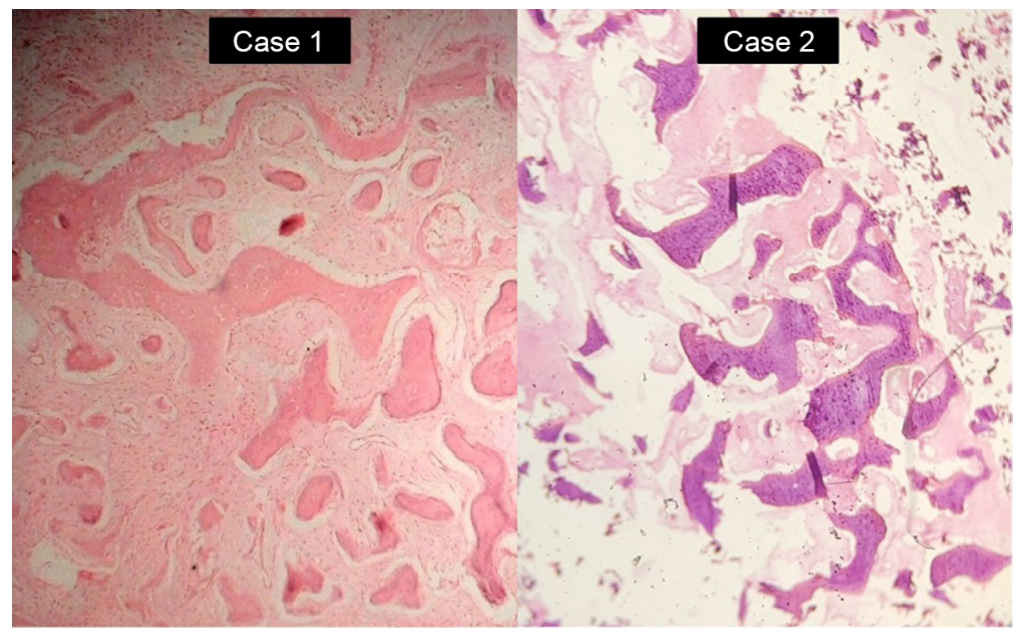

Figure 7 Histopathological sections of both cases revealing curvilinear-shaped bony trabeculae with the absence of osteoblastic rimming, seen dispersed within cellular loosely organized fibrous stroma.

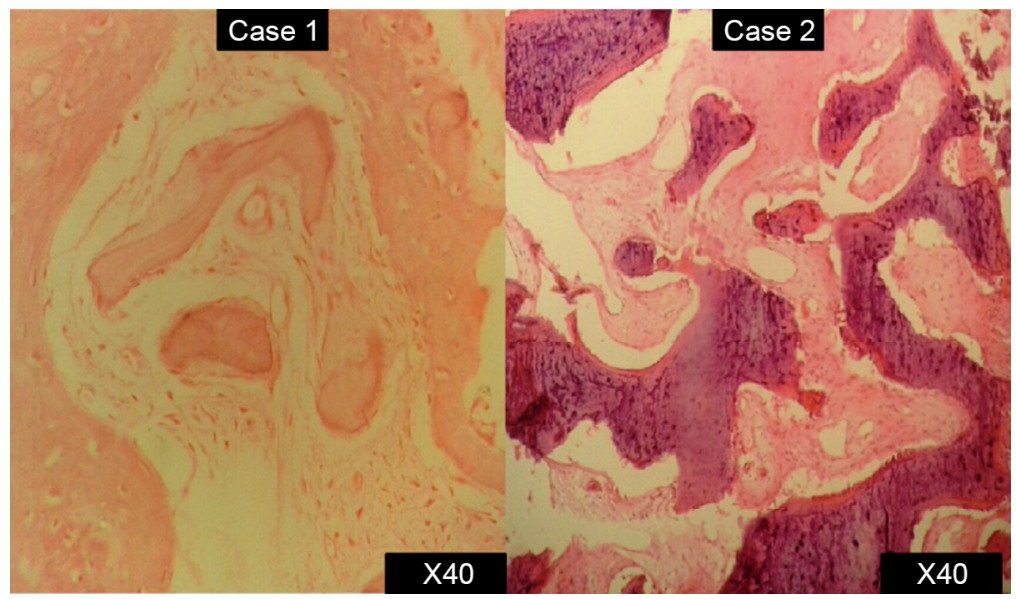

Figure 8 Histopathological sections of both cases at $\times 40$ magnification showing bony trabeculae with absence of osteoblastic rimming.

seen to occur more commonly in a unilateral distribution, involvement is asymmetric and generalized when the disease is bilateral. ${ }^{9}$
The polyostotic fibrous dysplasia can either be present in an isolated form or may present as a part of Jaffe-Lichtenstein syndrome where polyostotic fibrous dysplasia is 
seen along with Café-au-lait pigmentation or as a part of McCune-Albright syndrome where along with Café-au-lait pigmentation, multiple endocrinopathies such as sexual precocity, pituitary adenoma, or hyperthyroidism is also present. ${ }^{2}$

McCune-Albright syndrome was named after two physicians Donovan McCune and Fuller Albright, who individually described the triad in $1937 .^{10}$

The craniomaxillofacial form of fibrous dysplasia was described by Daves and Yardley for fibrous dysplasia involving two or more facial and skull bones. This form has shown around $13 \%$ prevalence. A lot of controversies exist whether to classify the craniomaxillofacial fibrous dysplasia into monostotic or polyostotic form. ${ }^{3,11,12}$ In a recent review, the authors proposed that craniofacial fibrous dysplasia involving the bones attached to each other and present in the same anatomic area, separated only by sutures, can be considered as monostotic only if no other bone in the body is involved. On the other hand, two separate anatomic areas within the craniofacial skeleton showing involvement must be categorized as polyostotic craniofacial dysplasia. ${ }^{3}$

However, the diagnostic gold standard for any disease is histopathology, but in the case of craniomaxillofacial fibrous dysplasia, many authors have claimed that radiography and CT play a remarkable role in diagnosis, treatment planning, and in follow-up of the case. ${ }^{3}$ Radiographically, ground glass appearance is seen with no visible trabecular pattern. Grossly the lesion is usually well circumscribed, dense with tan-gray color, and may vary in consistency from fibrous to gritty due to the presence of bone. Histologically, classical curvilinear trabeculae of the woven bone are seen surrounded highly by fibrocellular stroma. The bony trabeculae show the presence of osteocytes and no osteoblastic rimming. ${ }^{7}$

The diagnosis is made, largely based on the clinical features, radiographic features, and histopathological features. The biomarkers such as ALP and urinary hydroxyproline are not that effective for diagnosis rather can be used to see the response in case of non-surgical treatment of the disease.

Surgery in areas such as those involving the base of skull should be ideally considered in cases with functional impairment or when a cosmetic correction is needed. Since fibrous dysplasia is usually benign in nature, the surgery should be as conservative as possible. Considering the chances of recurrence of fibrous dysplasia, surgical procedures are better performed after puberty if not vital. In both cases, surgery was done for cosmetic reasons, and no attempt has been made to eradicate the lesion completely. ${ }^{11}$ Treatment involves surgical and nonsurgical therapies. In minor cases, bone osteoplasty at the site of involvement is adequate; however, in severe cases, complete excision with graft reconstruction should be considered. ${ }^{13}$

Patients of fibrous dysplasia should be made aware with its potential for malignant transformation that is approximately $1 \%$, specifically in cases with polyostotic form of fibrous dysplasia. ${ }^{14}$

\section{Conclusion}

Due to higher chances of the involvement of craniomaxillofacial region, fibrous dysplasia becomes more significant for dentists. Currently, the treatment is limited, but with better understanding of pathogenesis, the management can be improved. Both our cases did not show any malignant transformation till date and are under regular follow-up and monitoring through sensory nerve testing, photographs, and CT imaging to establish their growth rate of tumors. Being the first two cases from Nepal to be published, it becomes even more important as it can further help the dentists to become more aware in context of the diagnosis and treatment planning of such cases that will be reported hereafter.

\section{Declaration of patient consent}

Written informed consent was obtained from the patients for the publication of this case series and any accompanying images. A copy of the written consent is available for review by the editor-in-chief of this journal.

\section{Institutional approval}

Although not required, an informed approval was taken by the Chitwan Medical College Institutional Review Committee.

\section{Author contributions}

Both authors contributed to data analysis, drafting and revising the article, gave final approval of the version to be published, and agree to be accountable for all aspects of the work.

\section{Disclosure}

The authors report no conflicts of interest in this work.

\section{References}

1. Ozek C, Gundogan H, Bilkay U, Tokat C, Gurler T, Songur E. Craniomaxillofacial fibrous dysplasia. J Craniofac Surg. 2002;13(3):382-389.

2. Schwindinger WF, Francomano CA, Levine MA. Identification of a mutation in the gene encoding the alpha subunit of the stimulatory $\mathrm{G}$ protein of adenylyl cyclase in McCune-Albright syndrome. Proc Natl Acad Sci U S A. 1992;89(11):5152-5156.

3. Gupta D, Garg P, Mittal A. Computed Tomography in Craniofacial Fibrous Dysplasia: A Case Series with Review of Literature and Classification Update. Open Dent J. 2017;11:384-403.

4. Waldron CA. Fibro-osseous lesions of the jaws. J Oral Maxillofac Surg. 1993;51(8):828-835. 
5. Nilesh K, Punde P, Parkar MI. Craniofacial Fibrous Dysplasia of Zygomaticomaxillary Complex. World J Plast Surg. 2017;6(3):369-374.

6. Sumita M, Mala K, Karen B. Maxillofacial fibrous dysplasia. Indian J Dent Res. 2005;16(4):151-152.

7. Neville BW, Damm DD, Allen CM, Bouquot JE, editors. Oral and Maxillofacial Pathology. Philadelphia: Elsevier; 2002.

8. DiCaprio MR, Enneking WF. Fibrous dysplasia. Pathophysiology, evaluation, and treatment. J Bone Joint Surg Am. 2005;87(8):1848-1864.

9. Prada EJ, Hassan KH, Brandi ML, Falchetti A. Polyostotic form of fibrous dysplasia in a 13 years old Colombian girl showing clinical and biochemical response to neridronate intravenous therapy. Clin Cases Miner Bone Metab. 2009;6(3):264-265.
10. Riddle ND, Bui MM. Fibrous dysplasia. Arch Pathol Lab Med. 2013;137(1):134-138.

11. Daves ML, Yardley JH. Fibrous dysplasia of bone. Am J Med Sci. 1957;234(5):590-606.

12. Kontham R, Kontham U. Constricted path of closure: A diagnostic challenge. J Dent App. 2015;2(5):219-222.

13. Moore AT, Buncic JR, Munro IR. Fibrous dysplasia of the orbit in childhood. Clinical features and management. Ophthalmology. 1985;92(1):12-20.

14. Ruggieri P, Sim FH, Bond JR, Unni KK. Malignancies in fibrous dysplasia. Cancer. 1994;73(5):1411-1424.
Clinical, Cosmetic and Investigational Dentistry

\section{Publish your work in this journal}

Clinical, Cosmetic and Investigational Dentistry is an international, peer-reviewed, open access, online journal focusing on the latest clinical and experimental research in dentistry with specific emphasis on cosmetic interventions. Innovative developments in dental materials, techniques and devices that improve outcomes and patient satisfac-
Dovepress

tion and preference will be highlighted. The manuscript management system is completely online and includes a very quick and fair peerreview system, which is all easy to use. Visit http://www.dovepress. com/testimonials.php to read real quotes from published authors.

Submit your manuscript here: https://www.dovepress.com/clinical-cosmetic-and-investigational-dentistry-journal 